\title{
Association of heated tobacco product use and secondhand smoke exposure with suicidal ideation, suicide plans and suicide attempts among Korean adolescents: A 2019 national survey
}

\author{
Soyoon Park', Kang-Sook Lee ${ }^{1,2}$
}

\begin{abstract}
INTRODUCTION The consumption of heated tobacco products (HTPs) is increasing among adolescents worldwide. Although suicide and HTP use are linked, the association between suicide-related behavior, HTP use, and indirect smoking exposure are not yet properly studied. This study examined the association of HTP use and exposure to secondhand smoke (SHS) with suicidal ideation, suicide plans, and suicide attempts among South Korean adolescents.

METHODS Data from 57303 respondents (95.3\% response rate) were obtained from the 2019 Korean Youth Risk Behavior Web-based Survey. Chi-squared tests and multivariable logistic regression analyses were used to examine the association of HTP use and SHS exposure with suicidal ideation, suicide plans, and suicide attempts among adolescents. Multivariable logistic regression analyses included: Model 1, which was adjusted for demographic characteristics such as sex, school type, perceived school performance, economic status, and residence type; and Model 2, which was adjusted for demographics, depression, and drug use. RESULTS The risk of suicidal ideation was 1.37 (95\% CI: 1.10-1.70) and 1.44 (95\% CI: 1.18-1.75) times higher among HTP users who were exposed to SHS at home and at public places, respectively, compared to non-users. The risk of suicide attempts was 1.88 (95\% CI: 1.37-2.57), 1.45 (95\% CI: 1.63-2.00), and 2.21 (95\% CI: 1.63-3.00) times higher among HTP users exposed to SHS at home, school, and at public places, respectively.

CONCLUSIONS HTP use, and SHS exposure are likely indicators of risk behaviors. Our findings suggest possible directions for initiating, implementing, and evaluating programs and services to monitor HTP use and SHS exposure among Korean adolescents.
\end{abstract}

\section{AFFILIATION \\ 1 Department of Public Health, Graduate School, The Catholic University of Korea, Seoul, Korea \\ 2 Department of Preventive Medicine, College of Medicine, The Catholic University of Korea, Seoul, Korea}

CORRESPONDENCE TO Kang-Sook Lee. Department of Preventive Medicine, College of Medicine, The Catholic University of Korea, 222 Banpo-daero, Seocho-gu, Seoul 06591, Korea. E-mail: leekangs@catholic.ac.kr

KEYWORDS heated tobacco product, SHS, smoking, suicide, adolescents

Received: 5 January 2021 Revised: 14 June 2021 Accepted: 3 August 2021

\section{INTRODUCTION}

Suicide is a major mental health issue among adolescents worldwide ${ }^{1}$. Adolescent suicide is an alarming reality in South Korea, as well as globally. The suicide rate among Korean adolescents is twice the average rate reported in the Organization for Economic Cooperation and Development data, which makes it the highest among the 37 member countries. The suicide rate of Korean adolescents has progressively increased over the years, with a $17.8 \%$ increase from 2017 to a death rate of 9.1 per 100000 in $2018^{2}$. Korean adolescents (in 2019) faced suicide thoughts (13.1\%), had suicide plans $(4 \%)$, and suicide attempts $(3 \%)^{3}$. According to one study, $33.4 \%$ of people who think about suicide planned suicide, and $33.9 \%$ of those who think about suicide try to commit suicide ${ }^{4}$.

Several studies have reported an association between smoking and suicidal behaviors in adolescents $^{5-7}$ and conventional and e-cigarette consumption and exposure to SHS have been 
found to be significantly associated with adolescent suicidality ${ }^{5,8}$.

In Korea, ever use and current use of e-cigarettes among adolescents increased from 7.4 to $7.9 \%$ and from 2.2 to $2.7 \%$, respectively, between 2017 and $2018^{9}$. Results of recent research indicate that awareness, experience, and current use of heated tobacco products (HTPs) have rapidly increased among Korean young adults, with respondents believing that HTPs would help them quit smoking and are less harmful to their health than conventional cigarettes ${ }^{10}$.

E-cigarettes and HTPs are similar in certain aspects, such as the resemblance of the device and process. However, they are essentially different. E-cigarettes are battery-powered devices that deliver nicotine to the user through vaporization of a propylene-glycol solution, typically in combination with flavors ${ }^{11}$. In contrast, HTPs are defined as "tobacco products that produce aerosols containing nicotine and other chemicals that are inhaled by users through the mouth"12.

HTPs were introduced in Korea in June 2017, and the market share currently accounts for $10.8 \%$ of the total national tobacco market ${ }^{13}$. In the 2018 Korea Youth Risk Behavior Web-based Survey (KYRBWS), $81.3 \%$ of Korean youth respondents were smokers comprising traditional cigarettes, electronic cigarettes, and HTP users ${ }^{14}$.

A meta-analysis indicated an association between smoking and suicide possibly due to the biological pathway of smoking itself or relationship with other high-risk behaviors such as alcohol and drug dependency ${ }^{6}$. Furthermore, several studies have shown a significant association between depression and smoking ${ }^{15,16}$. Suicide is higher when one experiences pain and despair, and in this state, tobacco and drug use have been associated with increased suicide attempts ${ }^{17}$. Individuals experiencing suicidality tend to develop the ability to overcome the fear of death ${ }^{18,19}$. In a study of people aged 13-18 years who visited the emergency room in a suicide attempt, tobacco use increased ${ }^{20,21}$. Moreover, secondhand smoke ( $\mathrm{SHS}$ ) exposure location is significantly associated with depressive symptoms in former and current smokers ${ }^{22}$. In establishing a policy to prevent suicide of adolescents, active interventions of risk factors related to depression and smoking are needed $^{23}$.
In addition, another perspective that strengthens an association between cigarette use and suicidality stems from the generation of toxic constituents during cigarette use. Smoking reduces serotonin and monoamine oxidase levels, which can cause severe depression and suicide in some smokers ${ }^{24}$. HTPs release aerosols containing nicotine and toxic chemicals upon heating of tobacco without combustion ${ }^{25}$. Despite sufficient research that links tobacco use to suicide, the association between HTP use and suicide-related behaviors among adolescents has not been investigated. There is limited research on the association between HTP use, exposure to toxic constituents, and suicidality. A recent study found that HTPs might be used as a tool for suicide attempts ${ }^{26}$.

SHS requires attention in suicide research because studies have discovered that SHS exposure could be associated with suicide attempts, albeit weakly ${ }^{5}$, particularly with heavy exposure ( $>20$ cigarettes/ day) in some adolescents ${ }^{20}$. Exposure to SHS among children and adolescents increases their serum cotinine levels, which can induce anxiety and mental disorders ${ }^{27}$. However, the association of SHS experiences with suicidality in Korean adolescents has not been investigated.

This study aimed to examine the association between HTP use and suicidal ideation, suicide plans, and suicide attempts among Korean adolescents. In addition, this study investigated whether SHS exposure in different circumstances (e.g. home, school, and public places) and its interactions with HTP use are associated with suicidality.

\section{METHODS}

\section{Study population}

Data were obtained from the 2019 KYRBWS, which has been conducted annually by the Korea Centers for Disease Control and Prevention (KCDC) since 2005. The 2019 KYRBWS was conducted in April $2019^{10}$. The survey data are publicly available. All data analyses were conducted in accordance with KCDC guidelines. To obtain a nationally representative sample, the KYRBWS was administered with a stratified threestage random cluster sampling method. In the first stage, the study population was stratified according to the geographical region and school type to minimize any sampling error. In the second stage, 400 middle schools and 400 high schools were selected by 
proportional sampling to match the study population. In the third stage, the sample schools were sorted out using systematic sampling, and sample classes were chosen through simple randomization sampling of the selected schools. This web-based survey comprised 105 questions for 15 health-related areas, including cigarette use behavior and mental health. Participants did not fill in any personal information. This study was approved by the Institutional Review Board of the C University of Korea (MC20ZESI0102).

\section{Measurements}

Sociodemographic factors

Sociodemographic factors included the participants' sex, school type, self-perceived academic achievement in the past year, perceived economic status, and residence type. School types consisted of middle school and high school. Academic achievements and economic status included low, middle low, middle, middle high, and high categories. Residence types comprised that of immediate family, relatives, boarding house, dormitory, and social welfare care (Table 1).

\section{Lifetime and current cigarette use}

Study respondents were asked about their lifetime experience of conventional-cigarette-only use, e-cigarette use, and HTP-only use as a binary

Table 1. Participants’ general characteristics, South Korea, 2019 (N=57303)

\begin{tabular}{|c|c|c|c|c|}
\hline Variable & $\begin{array}{c}\text { All } \\
\left(\begin{array}{c}n=57303) \\
n(\%)\end{array}\right.\end{array}$ & $\begin{array}{c}\text { Male } \\
(n=29841) \\
n(\%)\end{array}$ & $\begin{array}{c}\text { Female } \\
\left(\begin{array}{c}n=27462) \\
n(\%)\end{array}\right.\end{array}$ & $p *$ \\
\hline \multicolumn{5}{|l|}{ School type } \\
\hline Middle & $29384(51.3)$ & $15401(51.6)$ & $13983(50.9)$ & 0.577 \\
\hline High & $27919(48.7)$ & $14440(48.4)$ & $13479(49.1)$ & \\
\hline \multicolumn{5}{|c|}{ Perceived academic achievement } \\
\hline High & 7647 (13.3) & $4661(15.6)$ & $2986(10.9)$ & $<0.001$ \\
\hline Middle high & $14296(25.0)$ & $7254(24.3)$ & $7042(25.6)$ & \\
\hline Middle & $17234(30.1)$ & 8615 (28.9) & $8619(31.4)$ & \\
\hline Middle low & $12570(21.9)$ & $6251(20.9)$ & $6319(23.0)$ & \\
\hline Low & $5556(9.7)$ & 3060 (10.3) & $2496(9.1)$ & \\
\hline \multicolumn{5}{|l|}{ Perceived economic status } \\
\hline High & $6379(11.1)$ & 4019 (13.5) & $2360(8.6)$ & $<0.001$ \\
\hline Middle high & $16126(28.2)$ & 8566 (28.7) & $7560(27.5)$ & \\
\hline Middle & $27457(47.9)$ & $13561(45.4)$ & $13896(50.6)$ & \\
\hline Middle low & $6042(10.5)$ & $2950(9.9)$ & 3092 (11.3) & \\
\hline Low & $1299(2.3)$ & $745(2.5)$ & $554(2.0)$ & \\
\hline \multicolumn{5}{|l|}{ Residence type } \\
\hline With immediate family & 54267 (94.7) & $28177(94.4)$ & $26090(95.0)$ & $<0.001$ \\
\hline With relatives & $332(0.6)$ & $197(0.7)$ & $135(0.5)$ & \\
\hline Boarding house & $347(0.6)$ & $215(0.7)$ & $132(0.5)$ & \\
\hline Dormitory & $2126(3.7)$ & $1111(3.7)$ & $1015(3.7)$ & \\
\hline Social welfare care setting & $231(0.4)$ & $141(0.5)$ & $90(0.3)$ & \\
\hline \multicolumn{5}{|l|}{ Depression } \\
\hline No & $41275(72.0)$ & 23346 (78.2) & $17929(65.3)$ & $<0.001$ \\
\hline Yes & $16028(28.0)$ & $6495(21.8)$ & $9533(34.7)$ & \\
\hline \multicolumn{5}{|l|}{ Drug use } \\
\hline No & 56700 (98.9) & 29515 (98.9) & 27185 (99.0) & 0.326 \\
\hline Yes & $603(1.1)$ & $326(1.1)$ & $277(1.0)$ & \\
\hline
\end{tabular}

${ }^{*} p<0.001$ indicates significant differences between the male and female groups in the results of the chi-squared tests. 
result (yes/no). Responses were measured with the questions: 'Have you ever taken even one puff of a cigarette in your lifetime?', 'Have you ever used e-cigarettes in your lifetime?', and 'Have you ever used HTPs in your lifetime?'. Only those who answered 'Yes' to lifetime cigarette use responded to current cigarette use. Participants were assessed for their current use of HTPs, conventional cigarettes, and e-cigarettes by asking: 'Have you used cigarettes in the past 30 days?', 'Have you used e-cigarettes in the past 30 days?', and 'Have you used HTPs in the past 30 days?'.

\section{SHS}

To assess SHS exposure, participants were asked: 'Have you been exposed to SHS at home in the past 7 days?', 'Have you been exposed to SHS at school in the past 7 days?', and 'Have you experienced SHS in public in the past 7 days?'.

\section{Depression}

This study included depression as a confounding variable in the experimental model because depression is known to be a significant factor for suicidality. The inclusion of this variable could reveal the true association of cigarette use with suicidality in this study by excluding the predictability of depression. Depression was assessed based on the question: 'Have you felt too sad or desperate to have a daily life for 2 weeks straight during the past 12 months?'. Binary response options of 'no' or 'yes' were used.

\section{Drug use}

Have you ever habitually or deliberately taken drugs, 'drank' butane gas, or 'bond'? Binary response options of 'no' or 'yes' were used.

\section{Suicidality}

Suicide-related perceptions and behaviors were measured with three questions about suicidal ideation, suicide plans, and suicide attempts as follows: 'Have you thought seriously about committing suicide in the past 12 months?', 'Have you made specific plans to commit suicide in the past 12 months?', and 'Have you attempted suicide in the past 12 months?'. Binary response options of no or yes were used.

\section{Statistical analyses}

The general characteristics of the study population and suicidality according to lifetime cigarette use, current cigarette use, and SHS experiences, were analyzed using chi-squared tests. Chi-squared tests were also used to determine significant differences among demographic characteristics, cigarette use, and SHS in sex-stratified analyses. Concerning the association between cigarette use and suicidality, chi-squared tests were used to ascertain significant differences by cigarette use and non-use.

To assess the association of current and lifetime use patterns with suicidal ideation, suicide plans, and suicide attempts, a multivariable logistic regression analysis was performed after adjusting for confounding variables (i.e. sex, school type, perceived school performance, economic status, residence type, and depression). Significance was set at $\mathrm{p}<0.05$. In the first test, demographic confounding variables were added. In the second test, demographics, depression, and drug use were added as confounders. The confounding variables were entered initially, and the independent variables were entered in the second regression model. The interaction effects between HTP use and SHS exposure for suicidality were tested by multiplying the lifetime HTP use and SHS exposure to predict suicidality. According to the variance inflation factor values, every variable had a value lower than 10; therefore, there was no collinearity. All statistical analyses were conducted using SPSS 25.0 (IBM, Armonk, NY, USA, 2017).

\section{RESULTS}

\section{Participants' general characteristics}

Table 1 presents participants' demographic characteristics. Of the 57303 participants, $51.3 \%$ were middle school students, and $48.7 \%$ were high school students. Most (94.7\%) lived with their immediate families, $0.6 \%$ lived with relatives, $0.6 \%$ lived in boarding houses, $3.7 \%$ lived in dormitories, and $0.4 \%$ lived in social welfare care settings. Further, $28 \%$ experienced depression and $1.1 \%$ used drugs.

Table 2 presents the smoking-related characteristics of the participants. Specifically, $11.3 \%$ of the participants had consumed cigarettes for lifetime use, and $52.2 \%$ used cigarettes currently. Moreover, $42.6 \%$ were currently using e-cigarettes, and $52.2 \%$ (51.6\% boys and $54.4 \%$ girls) were current HTP users. The SHS exposure locations were house, school, and public places in $32.2 \%, 21 \%$, and $51.7 \%$ of the cases, 
Table 2. Smoking-related characteristics of the participants, South Korea, 2019 (N=57303)

\begin{tabular}{|c|c|c|c|c|}
\hline Variable & $\begin{array}{c}\text { AII } \\
(n=57303) \\
n(\%)\end{array}$ & $\begin{array}{c}\text { Male } \\
(n=29841) \\
n(\%)\end{array}$ & $\begin{array}{c}\text { Female } \\
(n=27462) \\
n(\%)\end{array}$ & $p *$ \\
\hline \multicolumn{5}{|c|}{ Conventional cigarette } \\
\hline \multicolumn{5}{|c|}{ Lifetime use } \\
\hline No & $50227(87.7)$ & $24842(83.2)$ & $25385(92.4)$ & $<0.001$ \\
\hline Yes & 7076 (11.3) & 4999 (16.8) & 2077 (7.6) & \\
\hline \multicolumn{5}{|c|}{ Current use } \\
\hline No & 3383 (47.8) & 2369 (47.4) & $1014(48.8)$ & 0.273 \\
\hline Yes & 3693 (52.2) & $2630(52.6)$ & $1063(51.2)$ & \\
\hline \multicolumn{5}{|c|}{ E-cigarette } \\
\hline \multicolumn{5}{|c|}{ Lifetime use } \\
\hline No & $53268(93.0)$ & 26673 (89.4) & 26595 (96.8) & $<0.001$ \\
\hline Yes & $4035(7.0)$ & $3168(10.6)$ & 867 (3.2) & \\
\hline \multicolumn{5}{|c|}{ Current use } \\
\hline No & $2317(57.4)$ & $1861(58.7)$ & $456(52.6)$ & $<0.001$ \\
\hline Yes & $1718(42.6)$ & 1307 (41.3) & $411(47.4)$ & \\
\hline \multicolumn{5}{|l|}{ HTP } \\
\hline \multicolumn{5}{|c|}{ Lifetime use } \\
\hline No & $54630(95.3)$ & 27771 (93.1) & 26859 (97.8) & $<0.001$ \\
\hline Yes & $2673(4.7)$ & $2070(6.9)$ & $603(2.2)$ & \\
\hline \multicolumn{5}{|c|}{ Current use } \\
\hline No & 1277 (47.8) & $1002(48.4)$ & $275(45.6)$ & 0.226 \\
\hline Yes & $1396(52.2)$ & $1068(51.6)$ & $328(54.4)$ & \\
\hline \multicolumn{5}{|l|}{ SHS } \\
\hline \multicolumn{5}{|l|}{ Home } \\
\hline No & $38858(67.8)$ & $20998(70.4)$ & $17860(65.0)$ & $<0.001$ \\
\hline Yes & $18445(32.2)$ & $8843(29.6)$ & $9602(35.0)$ & \\
\hline \multicolumn{5}{|l|}{ School } \\
\hline No & $45270(79.0)$ & $23860(80.0)$ & $21410(78.0)$ & $<0.001$ \\
\hline Yes & $12033(21.0)$ & $5981(20.0)$ & $6052(22.0)$ & \\
\hline \multicolumn{5}{|c|}{ Public places } \\
\hline No & $27655(48.3)$ & $16257(54.5)$ & $11398(41.5)$ & $<0.001$ \\
\hline Yes & $29648(51.7)$ & $13584(45.5)$ & $16064(58.5)$ & \\
\hline \multicolumn{5}{|c|}{ Suicidality } \\
\hline Ideation & & & & $<0.001$ \\
\hline No & 49805 (86.9) & 27110 (90.8) & $22695(82.6)$ & \\
\hline Yes & $7498(13.1)$ & $2731(9.2)$ & 4767 (17.4) & \\
\hline Plan & & & & $<0.001$ \\
\hline No & $54997(96.0)$ & $28937(97.0)$ & $26060(94.9)$ & \\
\hline Yes & $2306(4.0)$ & $904(3.0)$ & $1402(5.1)$ & \\
\hline Attempt & & & & $<0.001$ \\
\hline No & $55572(97.0)$ & $29275(98.1)$ & 26297 (95.8) & \\
\hline Yes & 1731 (3.0) & 566 (1.9) & $1165(4.2)$ & \\
\hline
\end{tabular}

${ }^{*} p<0.001$ indicates significant differences between the male and female groups in the results of the chi-squared tests. 
respectively. The rates of suicide plans and attempts were $4 \%$ and $3 \%$, respectively. Female respondents were almost twice as likely as male respondents to have attempted suicide.

\section{Suicidality by cigarette use pattern}

Table 3 presents the prevalence of suicidality by cigarette-use pattern. The rates of suicide ideation, planning, and attempts for people who never used tobacco in their lifetime were $11.9 \%, 3.4 \%$, and $2.4 \%$, respectively; however, among those who were lifetime tobacco users, the proportions were $21.3 \%$,
$8.2 \%$, and $7.2 \%$, respectively $(\mathrm{p}<0.001)$. Among the current e-cigarette users, the rates of suicidal ideation, planning, and attempts were $26.7 \%, 12.9 \%$, and $12.4 \%$, respectively, which were significantly different from the proportions of $16.2 \%, 6.3 \%$, and $4.8 \%$, respectively, among non-users $(\mathrm{p}<0.001)$. In addition, $26.8 \%, 13.9 \%$, and $13.8 \%$ of the current HTP users experienced suicide thoughts, plans, and attempts, respectively, and the suicidal relevance was the highest among the types of cigarettes $(p<0.001)$. Suicide ideation, planning, and attempt rate were significantly associated with the place of exposure to

Table 3. Prevalence of suicidality by cigarette-use pattern among Korean adolescents, South Korea, 2019 $(\mathbf{N}=57303)$

\begin{tabular}{|c|c|c|c|c|c|c|c|c|c|}
\hline \multirow[t]{2}{*}{ Variable } & \multicolumn{2}{|c|}{$\begin{array}{l}\text { Suicidal ideation } \\
\qquad n(\%)\end{array}$} & \multirow[t]{2}{*}{$p *$} & \multicolumn{2}{|c|}{$\begin{array}{l}\text { Suicide plan } \\
\qquad n(\%)\end{array}$} & \multirow[t]{2}{*}{$p *$} & \multicolumn{2}{|c|}{$\begin{array}{l}\text { Suicide attempt } \\
\qquad n(\%)\end{array}$} & \multirow[t]{2}{*}{$p *$} \\
\hline & No & Yes & & No & Yes & & No & Yes & \\
\hline \multicolumn{10}{|c|}{ Conventional cigarette } \\
\hline \multicolumn{10}{|c|}{ Lifetime use } \\
\hline No & $44234(88.1)$ & $5993(11.9)$ & $<0.001$ & 48504 (96.6) & $1723(3.4)$ & $<0.001$ & 49004 (97.6) & $1223(2.4)$ & $<0.001$ \\
\hline Yes & 5571 (78.7) & 1505 (21.3) & & 6493 (91.8) & $583(8.2)$ & & $6568(92.8)$ & $508(7.2)$ & \\
\hline \multicolumn{10}{|c|}{ Current use } \\
\hline No & 2765 (81.7) & $618(18.3)$ & $<0.001$ & 3172 (93.8) & $211(6.2)$ & $<0.001$ & $3226(95.4)$ & $157(4.6)$ & $<0.001$ \\
\hline Yes & $2806(76.0)$ & $887(24.0)$ & & 3321 (89.9) & $372(10.1)$ & & $3342(90.5)$ & $351(9.5)$ & \\
\hline \multicolumn{10}{|c|}{ E-cigarette } \\
\hline \multicolumn{10}{|c|}{ Lifetime use } \\
\hline No & 44604 (87.5) & $6664(12.5)$ & $<0.001$ & 51331 (96.4) & $1937(3.6)$ & $<0.001$ & $51862(97.4)$ & $1406(2.6)$ & $<0.001$ \\
\hline Yes & 3201 (79.3) & 834 (20.7) & & 3666 (90.9) & $369(9.1)$ & & 3710 (91.9) & 325 (8.1) & \\
\hline \multicolumn{10}{|c|}{ Current use } \\
\hline No & $1942(83.8)$ & $375(16.2)$ & $<0.001$ & 2170 (93.7) & $147(6.3)$ & $<0.001$ & 2205 (95.2) & $112(4.8)$ & $<0.001$ \\
\hline Yes & 1259 (73.3) & $459(26.7)$ & & $1496(87.1)$ & 222 (12.9) & & 1505 (87.6) & $213(12.4)$ & \\
\hline \multicolumn{10}{|l|}{ HTP } \\
\hline \multicolumn{10}{|c|}{ Lifetime use } \\
\hline No & 44753 (87.4) & 6877 (12.6) & $<0.001$ & 52625 (96.3) & 2005 (3.7) & $<0.001$ & 53175 (97.3) & $1455(2.7)$ & $<0.001$ \\
\hline Yes & 2052 (76.8) & 621 (23.2) & & 2372 (88.7) & 301 (11.3) & & 2397 (89.7) & 276 (10.3) & \\
\hline \multicolumn{10}{|c|}{ Current use } \\
\hline No & 1030 (80.7) & 247 (19.3) & $<0.001$ & 1170 (91.6) & 107 (8.4) & $<0.001$ & 1193 (93.4) & $84(6.6)$ & $<0.001$ \\
\hline Yes & $1022(73.2)$ & $374(26.8)$ & & $1201(86.1)$ & 194 (13.9) & & 2397 (89.7) & 192 (13.8) & \\
\hline \multicolumn{10}{|l|}{ SHS } \\
\hline \multicolumn{10}{|l|}{ Home } \\
\hline No & 34432 (88.6) & 4426 (11.4) & $<0.001$ & 37566 (96.7) & 1292 (3.3) & $<0.001$ & 37927 (97.6) & $931(2.4)$ & $<0.001$ \\
\hline Yes & 15373 (83.3) & 3072 (16.7) & & 17431 (94.5) & $1014(5.5)$ & & 17645 (95.7) & $800(4.3)$ & \\
\hline \multicolumn{10}{|l|}{ School } \\
\hline No & 39890 (88.1) & 5380 (11.9) & $<0.001$ & 43717 (96.6) & 1553 (3.4) & $<0.001$ & $44130(97.5)$ & $1140(2.5)$ & $<0.001$ \\
\hline Yes & 9915 (85.4) & 2118 (17.6) & & 11280 (93.7) & 753 (6.3) & & 11441 (95.1) & $591(4.9)$ & \\
\hline \multicolumn{10}{|c|}{ Public places } \\
\hline No & 24865 (89.9) & 2790 (10.1) & $<0.001$ & 26788 (96.9) & 867 (3.1) & $<0.001$ & 27064 (97.9) & $591(2.1)$ & $<0.001$ \\
\hline Yes & $24940(84.1)$ & 4708 (15.9) & & 28209 (95.1) & $1439(4.9)$ & & 28508 (96.2) & $1140(3.8)$ & \\
\hline
\end{tabular}

${ }^{*} \mathrm{p}<0.001$ indicates significant differences between the user and non-user groups in the results of the chi-squared tests. 
SHS (16.7\%, 5.5\%, and $4.3 \%$, respectively), exposure at school $(17.6 \%, 6.3 \%$, and $4.9 \%$, respectively), and exposure at public places $(15.9 \%, 4.9 \%$, and $3.8 \%$, respectively; $\mathrm{p}<0.001)$. The rates of suicide ideation, plan, and attempts were $16.7 \%, 5.5 \%$, and $4.3 \%$, respectively, at home, and $17.6 \%, 6.3 \%$, and $4.9 \%$, respectively, at school as the SHS location; these were significantly different from the rates observed when home and school were not the SHS locations (all $\mathrm{p}<0.001$ ).

Association of suicidality with cigarette-use pattern Table 4 shows the results of the multivariable logistic regression analysis regarding suicidality according to the type of tobacco use. Model 1 was adjusted for sex, school type, perceived school performance, economic status, and residence type. In

Table 4. Association of cigarette use with suicidality, South Korea, 2019 ( $N=57303)$

\begin{tabular}{|c|c|c|c|c|c|c|c|}
\hline Variable & $\begin{array}{c}\text { Non-use } \\
\text { (Ref.) }\end{array}$ & $\begin{array}{l}\text { Suicidal ideation } \\
\text { AOR (95\% CI) }\end{array}$ & $p$ & $\begin{array}{l}\text { Suicide plan } \\
\text { AOR (95\% CI) }\end{array}$ & $p$ & $\begin{array}{l}\text { Suicide attempts } \\
\text { AOR (95\% CI) }\end{array}$ & $p$ \\
\hline \multicolumn{8}{|l|}{ Model $1^{\mathrm{a}}$} \\
\hline \multicolumn{8}{|l|}{ Lifetime use } \\
\hline Conventional cigarette & 1 & $2.10(1.92-2.29)$ & $<0.001$ & $2.17(1.89-2.50)$ & $<0.001$ & $2.71(2.32-3.17)$ & $<0.001$ \\
\hline E-cigarette & 1 & $1.08(0.95-1.23)$ & 0.242 & $1.25(1.03-1.52)$ & $<0.050$ & $1.31(1.05-1.63)$ & $<0.050$ \\
\hline HTP & 1 & $1.43(1.25-1.64)$ & $<0.001$ & $1.99(1.63-2.43)$ & $<0.001$ & $2.40(1.92-2.97)$ & $<0.001$ \\
\hline \multicolumn{8}{|l|}{ Current use } \\
\hline Conventional cigarette & 1 & $0.91(0.66-1.26)$ & 0.572 & $0.95(0.59-1.53)$ & 0.841 & $0.85(0.51-1.41)$ & 0.527 \\
\hline E-cigarette & 1 & $1.73(1.30-2.31)$ & $<0.001$ & $2.06(1.34-3.15)$ & $<0.010$ & $2.26(1.44-3.57)$ & $<0.001$ \\
\hline HTP & 1 & $1.25(0.93-1.68)$ & 0.134 & $1.29(0.85-1.96)$ & 0.232 & $1.70(1.08-2.67)$ & $<0.050$ \\
\hline \multicolumn{8}{|l|}{ SHS } \\
\hline Home & 1 & $1.29(1.22-1.36)$ & $<0.001$ & $1.38(1.27-1.51)$ & $<0.001$ & $1.43(1.29-1.58)$ & $<0.001$ \\
\hline School & 1 & $1.39(1.31-1.48)$ & $<0.001$ & $1.70(1.55-1.87)$ & $<0.001$ & $1.78(1.60-1.87)$ & $<0.001$ \\
\hline Public places & 1 & $1.38(1.31-1.45)$ & $<0.001$ & $1.24(1.13-1.36)$ & $<0.001$ & $1.38(1.24-1.53)$ & $<0.001$ \\
\hline \multicolumn{8}{|l|}{$\mathrm{HTP}+\mathrm{SHS}$} \\
\hline HTP + SHS home & 1 & $1.74(1.43-2.13)$ & $<0.001$ & $2.07(1.57-2.73)$ & $<0.001$ & $2.57(1.91-3.47)$ & $<0.001$ \\
\hline HTP + SHS school & 1 & $1.46(1.18-1.79)$ & $<0.001$ & $2.06(1.55-2.73)$ & $<0.001$ & $1.94(1.44-2.60)$ & $<0.001$ \\
\hline HTP + SHS public places & 1 & $1.78(1.48-2.14)$ & $<0.001$ & $2.04(1.55-2.68)$ & $<0.001$ & $2.76(2.04-3.71)$ & $<0.001$ \\
\hline \multicolumn{8}{|l|}{ Model $2^{b}$} \\
\hline \multicolumn{8}{|l|}{ Lifetime use } \\
\hline Conventional cigarette & 1 & $1.64(1.49-1.80)$ & $<0.001$ & $1.63(1.42-1.88)$ & $<0.001$ & $2.00(1.71-2.34)$ & $<0.001$ \\
\hline E-cigarette & 1 & $0.99(0.86-1.14)$ & 0.866 & $1.10(0.90-1.35)$ & 0.368 & $1.16(0.93-1.46)$ & 0.194 \\
\hline HTP & 1 & $1.20(1.03-1.40)$ & $<0.050$ & $1.56(1.26-1.93)$ & $<0.001$ & $1.90(1.51-2.39)$ & $<0.001$ \\
\hline \multicolumn{8}{|l|}{ Current use } \\
\hline Conventional cigarette & 1 & $0.98(0.93-1.04)$ & 0.480 & $1.00(0.92-1.08)$ & 0.961 & $1.02(0.94-1.10)$ & 0.683 \\
\hline E-cigarette & 1 & $1.12(1.04-1.21)$ & $<0.010$ & $1.19(1.08-1.32)$ & $<0.010$ & $1.19(1.07-1.32)$ & $<0.010$ \\
\hline HTP & 1 & $1.04(0.96-1.12)$ & 0.372 & $1.06(0.95-1.17)$ & 0.314 & $1.05(0.95-1.17)$ & 0.349 \\
\hline \multicolumn{8}{|l|}{ SHS } \\
\hline Home & 1 & $1.19(1.12-1.26)$ & $<0.001$ & $1.22(1.12-1.34)$ & $<0.001$ & $1.25(1.13-1.39)$ & $<0.001$ \\
\hline School & 1 & $1.18(1.11-1.26)$ & $<0.001$ & $1.39(1.29-1.53)$ & $<0.001$ & $1.43(1.27-1.60)$ & $<0.001$ \\
\hline Public places & 1 & $1.20(1.13-1.27)$ & $<0.001$ & $1.05(0.96-1.16)$ & 0.314 & 1.16 (1.04-1.30) & $<0.010$ \\
\hline \multicolumn{8}{|l|}{ HTP + SHS } \\
\hline HTP + SHS home & 1 & $1.37(1.10-1.70)$ & $<0.010$ & $1.45(1.09-1.95)$ & $<0.050$ & $1.88(1.37-2.57)$ & $<0.001$ \\
\hline HTP + SHS school & 1 & $1.21(0.96-1.52)$ & 0.108 & $1.57(1.16-2.12)$ & $<0.010$ & $1.45(1.06-2.00)$ & $<0.050$ \\
\hline HTP + SHS public places & 1 & $1.44(1.18-1.75)$ & $<0.001$ & $1.64(1.23-2.17)$ & $<0.001$ & $2.21(1.63-3.00)$ & $<0.001$ \\
\hline
\end{tabular}

a Model 1 was adjusted for sex, school type, perceived school performance, economic status, and residence type. Model fit statistics were: $\chi^{2}=194.495-656.331$, df $=3$, $p<0.001$, Nagelkerke $R^{2}=0.055-0.135$ for suicidal ideation; $x^{2}=31.512-486.223, d f=3, p<0.001$ and Nagelkerke $R^{2}=0.042-0.176$ for suicide $p$ lan; and $x^{2}=48.631-633.291, d f=3, p<0.001$, Nagelkerke $R^{2}=0.065-0.206$ for suicide attempts. $b$ Model 2 was adjusted for depression, and drug use, along with all factors that were adjusted in Model 1 . Model fit statistics were: $X^{2}=476.314-8811.696, d f=10, p<0.001$, Nagelkerke $R^{2}=0.261-309$ for suicidal ideation; $x^{2}=367.766-3268.573, d f=10, p<0.001, N a g e l k e r k e ~ R^{2}=0.188-0.327$ for suicide plan; $X^{2}=361.876-3076.672, d f=10, p<0.001$, Nagelkerke $R^{2}=0.206-0.331$ for suicide attempts. 
Model 1, the lifetime users of HTPs were 2.4 times more likely to report suicide attempts $(\mathrm{AOR}=2.40$; 95\% CI: 1.92-2.97, p<0.001) than non-smokers, and recent HTP users were 1.7 times more likely to report suicide attempts $(\mathrm{AOR}=1.70 ; 95 \%$ CI: $1.08-2.67$, $\mathrm{p}<0.05)$. Participants who experienced SHS at home demonstrated significantly higher suicidal ideation $(\mathrm{AOR}=1.29 ; 95 \% \mathrm{CI}: 1.22-1.36, \mathrm{p}<0.001)$, planning $(\mathrm{AOR}=1.38 ; 95 \% \mathrm{CI}: 1.27-1.51, \mathrm{p}<0.001)$, and attempts $(\mathrm{AOR}=1.43 ; 95 \% \mathrm{CI}: 1.29-1.58, \mathrm{p}<0.001)$ than those who were not exposed to SHS at home. Among HTP users who were exposed to SHS at home, school, and at public places, the likelihood of suicide attempts was 2.57 (95\% CI: 1.91-3.47, p<0.001), 1.94 (95\% CI: $1.44-2.60, \mathrm{p}<0.001)$, and $2.76(95 \%$ CI: 2.04-3.71, p<0.001) times higher, respectively.

Model 2 controlled for depression and drug use along with all the factors controlled in Model 1 . For the use of tobacco adjusted for demographic, depression, and drug use in Model 2, the results were similar to those of Model 1, except for a few associations. Lifetime users of HTPs were 1.9 times more likely to report suicide attempts than the nonusers (95\% CI: 1.51-2.39, p<0.001). Participants were exposed to SHS at home and school, the risks of suicide attempts were 1.25 (95\% CI: $1.13-1.39$, $\mathrm{p}<0.001)$ and 1.43 (95\% CI: $1.27-1.60, \mathrm{p}<0.001)$ times higher, respectively, than those who were not exposed. When HTP users were exposed to SHS at home, the risks of suicidal ideation ( $\mathrm{AOR}=1.37$; $95 \%$ CI: $1.10-1.70, \mathrm{p}<0.01)$ and suicide plan $(\mathrm{AOR}=1.45$; 95\% CI: $1.09-1.95, \mathrm{p}<0.05)$ were significant. Similarly, when HTP users were also exposed to SHS at public places, the likelihood of suicide ideation (AOR $=1.44 ; 95 \%$ CI: $1.18-1.75, \mathrm{p}<0.001)$ and suicide plans $(\mathrm{AOR}=1.64 ; 95 \%$ CI: $1.23-2.17, \mathrm{p}<0.001)$ were significantly higher compared to HTP users who were not exposed to SHS. When HTP users were exposed to SHS, the likelihood of suicide attempt was 1.88 (95\% CI: $1.37-2.57, \mathrm{p}<0.001)$ times higher when exposure was at home, 1.45 (95\% CI: 1.63-2.00, $\mathrm{p}<0.05)$ times higher at school, and $2.21(95 \%$ CI: $1.63-3.00, \mathrm{p}<0.001)$ times higher at public places.

\section{DISCUSSION}

The nationwide youth survey found that adolescents using HTPs at least once in their lives had a higher likelihood of suicidal thoughts, suicide plans, and suicide attempts. When HTP users were also exposed to SHS at home and at public places, the likelihood of suicidal ideation was 1.37 and 1.44 times higher, respectively. When HTP users were exposed to SHS, the likelihood of reported suicide attempts increased by 1.88 times at home, 1.45 times at school, and 2.21 times at public places.

According to a study on the relationship between e-cigarette use and suicide in adolescents, suicidal ideation, suicide plans, and serious suicide attempts increased by 1.58, 2.44, 3.09 times, respectively, in the adolescents who used e-cigarettes compared to those who did not use e-cigarettes in the past 30 days ${ }^{28}$. In another study, smoking was a predominant factor affecting suicide thoughts, plans, and attempts of adolescents; the number of cigarettes smoked was related to suicide ${ }^{29}$. The current study demonstrated that smoking was an important factor that affected suicidal ideation, plans, and attempts among adolescents. Furthermore, the amount of smoking was related to suicide, making our findings consistent with recent studies.

In a meta-analysis of prospective cohort studies for evaluation of cigarette smoking and risk of completed suicide, current smokers had a 1.81-fold higher risk of suicide than non-smokers, and a 24 percent increase in the risk of suicide was observed with each increment of 10 cigarettes per day ${ }^{30}$. Similar to the results of previous studies, in our study, the likelihood of reporting suicide attempts was 2.71 times higher in lifetime tobacco users and 2.4 times higher in lifetime HTP users than non-smokers. Furthermore, these results showed that the suicide attempt rates were 2.0 and 1.9 times higher among lifetime tobacco and HTP users, respectively, even after controlling for depression and drug use as additional confounding variables. However, the AORs for suicide attempts in lifetime e-cigarette users were not significant. In our study, indirect smoking at home, schools, and public places was associated with suicide, which was significant even after adjusting for depression and drug use. The likelihood of suicidal ideation, plans, and attempts were higher for those who used HTPs in addition to exposure to SHS than those who were exposed to SHS only.

HTP users perceive that HTPs are less harmful than traditional cigarettes, however further research is needed as HTPs contain a higher level of tar 
than conventional cigarettes, which contradicts this assumption $^{31}$. Recently, the use of HTPs in Koreans has increased continuously, with $90 \%$ of HTP users consuming e-cigarettes or conventional cigarettes, simultaneously. Currently, HTP users in Korea are likely to be multiple users ${ }^{32}$. Furthermore, smokers also use e-cigarettes and HTPs together. However, in a 2014 meta-analysis, the rate of success in smoking cessation fell to 39 per cent ${ }^{33}$. Another meta-analysis conducted in 2016 showed that e-cigarette users had a $28 \%$ lower success in stopping smoking than people who did not use e-cigarettes ${ }^{29}$.

In a study of New Zealanders aged 15-21 years, people looking for new tobacco products, such as e-cigarettes and HTPs, increase their suicidal behavior in adolescence, even controlling for variables such as mental health and depression ${ }^{34}$. Adolescence is a period when the development of the brain circuit that regulates cognition and emotion is vulnerable to the effects of nicotine and tobacco use. Exposure to harmful ingredients can cause anxiety and depression in adolescents ${ }^{20,21,35}$. The causal relationship between nicotine and suicide is unclear, but nicotine exposure disrupts the brain dopamine pathway, increasing stress and depressive symptoms ${ }^{36}$.

Addiction to nicotine can lead to awareness of $\mathrm{HTPs}^{10}$ and behavior related to suicide, and tobacco use increases the risk of suicide. Moreover, it has been reported that smoking initiation at a younger age increased nicotine dependence and negatively affected mental health ${ }^{37}$. Smokers have been found to have lower cerebrospinal fluid levels of serotonin metabolites. In a study, smokers showed a 2.6-fold higher suicide attempt risk, lower cerebrospinal fluid levels of serotonin metabolites, and lower platelet monoamine oxidases ${ }^{38}$. Lower serotonin levels could cause depression and increase aggressive and impulsive behavior depending on their existing characteristics and temperaments.

Another probable factor regarding HTP use in Korea might be adolescents' accessibility to cigarettes. The Korean Youth Protection Act banned the access of cigarettes for adolescents, however, a recent survey found that $69.9 \%$ and $66.4 \%$ of male and female adolescents, respectively, who attempted to purchase cigarettes were able to obtain them at convenience stores $^{9}$. The availability of HTPs since 2017 and closed system e-cigarette vapor products (e.g. JUUL) since 2019 in Korea has transformed Korea's tobacco market, capturing $11.8 \%$ of the market share in $2019^{39}$; this suggests that regulations on adolescent access to e-cigarettes are still lacking. Therefore, providing Korean adolescents with proper interventional and preventive programs for both HTP use and mental disorders may facilitate better identification of risk symptoms, including suicide-related perceptions and behaviors.

\section{Limitations}

This study has some limitations. First, this crosssectional study design precluded the detection of any causal associations between HTP use and suicidality and hence only associations can be assessed. Future research should include a longitudinal panel analysis to examine the influence of cigarette-use behaviors on subsequent suicidality. Second, the respondents might have overrated socially desirable responses (e.g. school grades) and underrated negative responses (e.g. cigarette use and suicidality), which may have caused response biases. Third, the use of cigarettes and HTPs was assessed based on a single item, which asked participants to choose a binary response between ever or never use. The single item would neither fully represent the respondents' cigaretteuse habits nor was it derived from scales that were validated in earlier studies. Therefore, the measures of cigarette use, SHS exposure, suicidal ideation, suicide plans, and suicide attempts need to be further validated in future research. Fourth, multifaceted aspects of HTP use and risk behaviors predicting suicidal ideation, suicide plans, and suicide attempts were not investigated in this study. Cigarette use, substance use, and other psychological factors could possibly explain suicidality ${ }^{40}$. Fifth, additional mental disorder factors, such as psychosis and loneliness, could be included in the analysis as confounders. With the inclusion of the relevant variables, the true associations between HTP use, SHS exposure, and suicidality can be verified.

\section{CONCLUSIONS}

This study revealed the possibility that Korean adolescents with HTP use and SHS exposure may have other risk symptoms that are associated with and predict suicidal ideation, suicide plans, and suicide attempts. The results call for an evaluation 
and intervention amid the expansion of HTP use in the Korean adolescent population. Policymakers and healthcare professionals should initiate cigarette-use cessation programs that include HTP use and SHS exposure for adolescents. Through screening efforts, adolescents with HTP use, SHS exposure, mental health risk factors, and suicidality could receive targeted interventions. The government can refine policies on adolescents' access to tobacco products, including HTPs, e-cigarettes, and conventional cigarettes. National campaigns, such as those for parental mediation and awareness of SHS, can be implemented. The results of this study indicate directions for initiating, implementing, and evaluating programs and services for HTP use and SHS exposure in Korean adolescents. HTP use and SHS exposure may help explain risk behaviors that may motivate suicide-related perceptions and behaviors.

\section{REFERENCES}

1. Centers for Disease Control and Prevention. Adolescent health. Accessed August 1, 2020. https://www.cdc.gov/ nchs/fastats/adolescent-health.htm

2. Organization for Economic Co-Operation and Development. Suicide rates. Accessed August 21, 2020. https://data.oecd.org/healthstat/suicide-rates.htm

3. Ministry of Education, Ministry of Health and Welfare, Korea Centers for Disease Control and Prevention. The 15th Korea Youth Risk Behavior Web-Based Survey. Accessed June 6, 2021. http://www.kdca.go.kr/yhs/

4. Nock MK, Green JG, Hwang I, et al. Prevalence, correlates, and treatment of lifetime suicidal behavior among adolescents: results from the National Comorbidity Survey Replication Adolescent Supplement. JAMA Psychiatry. 2013;70(3):300-310. doi:10.1001/2013.jamapsychiatry.55

5. Lange S, Koyanagi A, Rehm J, Roerecke M, Carvalho AF. Association of tobacco use and exposure to SHS with suicide attempts among adolescents: findings from 33 countries. Nicotine Tob Res. 2020;22(8):1322-1329. doi:10.1093/ntr/ntz172

6. Poorolajal J, Darvishi N. Smoking and Suicide: A Meta-Analysis. PLoS One. 2016;11(7):e0156348. doi:10.1371/journal.pone.0156348

7. Bohnert KM, Ilgen MA, McCarthy JF, Ignacio RV, Blow FC, Katz IR. Tobacco use disorder and the risk of suicide mortality. Addiction. 2014;109(1):155-162. doi:10.1111/add.12381

8. Lee Y, Lee KS. Association of Depression and Suicidality with Electronic and Conventional Cigarette Use in South Korean Adolescents. Subst Use Misuse. 2019;54(6):934943. doi:10.1080/10826084.2018.1552301

9. Ministry of Education, Ministry of Health and Welfare,
Korea Centers for Disease Control and Prevention. The 14th Korea Youth Risk Behavior Web-Based Survey. Accessed August 23, 2020. http://www.kdca.go.kr/yhs/

10. Kim J, Yu H, Lee S, Paek YJ. Awareness, experience and prevalence of heated tobacco product, IQOS, among young Korean adults. Tob Control. 2018;27(Suppl 1):s74-s77. doi:10.1136/tobaccocontrol-2018-054390

11. Grana RA, Ling PM, Benowitz N, Glantz S. Electronic cigarettes. Circulation. 2014;129(19):e490-e492. doi:10.1161/CIRCULATIONAHA.114.008545

12. World Health Organization. Heat-not-Burn tobacco products information sheet. Accessed August 25, 2020. https://apps.who.int/tobacco/publications/prod_ regulation/heat-not-burn-products-information-sheet/ en/index.html

13. Korean Ministry of Economy and Finance. [Tobacco Market Trends]. Published January 22, 2020. Accessed, August 23, 2020. http://www.moef.go.kr/nw/nes/detailNesDtaView. do? menuNo $=4010100 \&$ searchNttId $1=$ MOSF_000000 000029264\&searchBbsId1=MOSFBBS_000000000028

14. Kang SY, Lee S, Cho HJ. Prevalence and predictors of heated tobacco product use and its relationship with attempts to quit cigarette smoking among Korean adolescents. Tob Control. 2021;30(2):192-198. doi:10.1136/tobaccocontrol-2019-055114

15. Park S, Romer D. Associations between smoking and depression in adolescence: an integrative review. Taehan Kanho Hakhoe Chi. 2007:37(2):227-241. doi:10.4040/jkan.2007.37.2.227

16. Paperwalla KN, Levin TT, Weiner J, Saravay SM. Smoking and depression. Med Clin N Am. 2004;88(6):1483-1494. doi:10.1016/j.mcna.2004.06.007

17. Anderson AM, Happ MB. The three-step theory of suicide: analysis and evaluation. ANS Adv Nurs Sci. 2021;44(1):89100. doi:10.1097/ANS.0000000000000337

18. Kyron MJ, Carrington-Jones P, Page AC, Bartlett J, Lawrence D. Factors differentiating adolescents who consider suicide and those who attempt: Results from a National Survey of Australian Adolescents. Aust J Psychol. 2020;72(2):145-155. doi:10.1111/ajpy.12267

19. Imperato PJ. The administration of a public health agency. A case study of the New York City Department of Health. Human Sciences Press;1983: 26-62.

20. Chen VCH, Kuo CJ, Wang TN, et al. Suicide and other-cause mortality after early exposure to smoking and secondhand smoking: a 12-year population-based follow-up study. Plos One. 2015;10(7):e0130044. doi:10.1371/journal.pone.0130044

21. Baiden P, LaBrenz CA, Asiedua-Baiden G, Muehlenkamp JJ. Examining the intersection of race/ethnicity and sexual orientation on suicidal ideation and suicide attempt among adolescents: findings from the 2017 Youth Risk Behavior Survey. J Psychiatr Res. 2020;125:13-20. doi:10.1016/j.jpsychires.2020.02.029

22. Jang BN, Jeong W, Kang SH, Jang SI. Association 
between the location of SHS exposure and depressive symptoms among South Korean adolescents. Int J Environ Res Public Health. 2020;17(14):5116. doi:10.3390/ijerph17145116

23. Im Y, Oh WO, Suk M. Risk Factors for Suicide Ideation Among Adolescents: Five-Year National Data Analysis. Arch Psychiatr Nurs. 2017;31(3):282-286. doi:10.1016/j.apnu.2017.01.001

24. Hughes JR. Smoking and suicide: a brief overview. Drug Alcohol Depend. 2008;98:169-178. doi:10.1016/j.drugalcdep.2008.06.003

25. Auer R, Concha-Lozano N, Jacot-Sadowski I, Cornuz J, Berthet A. Heat-not-burn tobacco cigarettes: smoke by any other name. JAMA Intern Med. 2017;177(7):10501052. doi:10.1001/jamainternmed.2017.1419

26. Obertova N, Navratil T, Zak I, Zakharov S. Acute exposures to e-cigarettes and heat-not-burn products reported to the Czech Toxicological Information Centre over a 7-year period (2012-2018). Basic Clin Pharmacol Toxicol. 2020;127(1):39-46. doi:10.1111/bcpt.13393

27. Hamer M, Ford T, Stamatakis E, Dockray S, Batty GD. Objectively measured secondhand smoke exposure and mental health in children: evidence from the Scottish Health Survey. Arch Pediatr Adolesc Med. 2011;165(4):326-331. doi:10.1001/archpediatrics.2010.243

28. Kim JS, Kim K. Electronic cigarette use and suicidal behaviors among adolescents. J Public Health (Oxf). 2021;43(2):274-280. doi:10.1093/pubmed/fdz086

29. Kalkhoran S, Glantz SA. E-cigarettes and smoking cessation in real-world and clinical settings: a systematic review and meta-analysis. Lancet Respir Med. 2016;4(2):116-128. doi:10.1016/S2213-2600(15)00521-4

30. Li D, Yang X, Ge Z, et al. Cigarette smoking and risk of completed suicide: a meta-analysis of prospective cohort studies. J Psychiatr Res. 2012;46(10):1257-1266. doi:10.1016/j.jpsychires.2012.03.013

31. O'Brien RM. A caution regarding rules of thumb for variance inflation factors. Qual Quant. 2007;41(5):673690. doi:10.1007/s11135-006-9018-6

32. Kim SH, Cho HJ. Prevalence and correlates of current use of heated tobacco products among a nationally representative sample of Korean adults: Results from a cross-sectional study. Tob Induc Dis. 2020;18(August). doi:10.18332/tid/125232

33. Grana R, Benowitz N, Glantz SA. E-cigarettes: a scientific review. Circulation. 2014;129(19):1972-1986. doi:10.1161/CIRCULATIONAHA.114.007667

34. Fergusson DM, Woodward LJ, Horwood LJ. Risk factors and life processes associated with the onset of suicidal behaviour during adolescence and early adulthood. Psychol Med. 2000;30(1):23-39. doi:10.1017/s003329179900135x

35. Spear LP. The adolescent brain and age-related behavioral manifestations. Neurosci Biobehav Rev. 2000;24(4):417463. doi:10.1016/s0149-7634(00)00014-2
36. Lechner WV, Janssen T, Kahler CW, AudrainMcGovern J, Leventhal AM. Bi-directional associations of electronic and combustible cigarette use onset patterns with depressive symptoms in adolescents. Prev Med. 2017;96:73-78. doi:10.1016/j.ypmed.2016.12.034

37. DeBry SC, Tiffany ST. Tobacco-induced neurotoxicity of adolescent cognitive development (TINACD): a proposed model for the development of impulsivity in nicotine dependence. Nicotine Tob Res. 2008;10(1):1-25. doi:10.1080/14622200701767811

38. Malone KM, Waternaux G, Haas GL, Cooper TB, Li S, Mann JJ. Cigarette smoking, suicidal behavior, and serotonin function in major psychiatric disorders. Am J Psychiatry. 2003;160(4):773-779. doi:10.1176/appi.ajp.160.4.773

39. U.S. Food and Drug Administration. 2018 NYTS Data: A Startling Rise in Youth E-Cigarette Use. Accessed August 1, 2020. http://www.fda.gov/tobacco-products/ youth-and-tobacco/2018-nyts-data-startling-rise-youthe-cigarette-use

40. Bağrul D, Arıkan Fi். The relationship between suicide attempt and smoking, alcohol and substance use and psychosocial characteristics in adolescents. Cumhuriyet Tıp Dergisi. 2020;42(1):71-78. doi:10.7197/cmj.vi.553903

\section{CONFLICTS OF INTEREST}

The authors have completed and submitted the ICMJE Form for Disclosure of Potential Conflicts of Interest and none was reported.

\section{FUNDING}

There was no source of funding for this study.

ETHICAL APPROVAL AND INFORMED CONSENT

This study was approved by the Institutional Review Board of the Catholic University of Korea (approval no. MC20ZESI0102, 11 September 2020). Informed consent was not required as the data used were from an existing database.

\section{DATA AVAILABILITY}

The data supporting this study are available at the following link http://www.kdca.go.kr/yhs/home.jsp. Data were obtained from the 2019 KYRBWS, which has been conducted annually by the Korea Centers for Disease Control and Prevention (KCDC).

\section{AUTHORS' CONTRIBUTIONS}

SP designed the study under the direction of KSL. SP gathered descriptive statistics and conducted the statistical analyses under the guidance of KSL. SP wrote the first draft of the manuscript that was subsequently reviewed and edited. SP and KSL have read and approved the final manuscript.

\section{PROVENANCE AND PEER REVIEW}

Not commissioned; externally peer reviewed. 